\title{
carta ao editor
}

LOPES, C.A.; ÁVILA, A.C. Informações inadequadas sobre resistência a doenças em catálogos de cultivares de hortaliças: um exemplo para tomate e pimentão. Horticultura Brasileira, Brasília, v. 20, n. 2, p. 130-132, junho 2.002.

\section{Informações inadequadas sobre resistência a doenças em catálogos de cultivares de hortaliças: um exemplo para tomate e pimentão}

\author{
Carlos Alberto Lopes; Antônio Carlos de Ávila \\ Embrapa Hortaliças, C. Postal 218, 70.359-970 Brasília, DF; E-mail: clopes@cnph.embrapa.br
}

Palavras-chave: Lycopersicon esculentum, Capsicum annuum, melhoramento de plantas.

Keywords: Lycopersicon esculentum, Capsicum annuum, plant breeding.

(Aceito para publicação em 01 de março de 2.002)

$\mathrm{P}$ ublicações contendo informações sobre cultivares novas ou disponíveis para comercialização são muito apreciadas por produtores, pesquisadores, professores e estudantes. Cientes disso, as companhias que produzem ou comercializam sementes de hortaliças publicam catálogos e folhetos de excelente qualidade visual, explorando habilmente a beleza deste grupo de alimentos.

Dentre as diversas características varietais descritas em catálogos, uma das informações mais demandadas é a indicação de resistência a doenças. De fato, através da resistência genética temse a maneira mais prática de se controlar as doenças: o controle já vem "embutido" na semente adquirida, com a vantagem de reduzir a contaminação do ambiente e dos alimentos pelo uso dos agrotóxicos. Para a finalidade desta carta, resistência genética é "a capacidade da planta de inibir, total ou parcialmente, o efeito deletério de um patógeno ou outro fator danoso aos seus tecidos". Desta maneira, o termo tolerância deve ser evitado para substituir a resistência parcial.

Apesar de acreditarmos que a denominação mais correta seja resistência à doença, em vez de resistência ao patógeno (já que o que se avalia é o fenótipo), esta última forma, de maneira abreviada, é aceita e até sugerida na confecção de catálogos. Isto porque ela permite a indicação de resistência restrita a alguma(s) variante(s) do patógeno, como espécies, subespécies, raças, estirpes, patovares ou biovares. Afinal, a utilização de abreviaturas já é muito usada para identificar doenças causadas por espécies de vírus. Para fungos, bactérias e nematóides, entretanto, é essencial que haja uma legenda explicativa das abreviaturas para evitar interpretações erradas ou o uso de nomes de doenças conhecidos apenas regionalmente.

Infelizmente para a maioria dos casos, a baixa qualidade das informações referentes à resistência a doenças contrastam com a alta qualidade visual dos catálogos e folhetos, ou mesmo com as características positivas das cultivares que são apresentadas. De um modo geral, estas informações são incorretas ou incompletas, e portanto inadequadas, deixando o leitor desinformado ou, na melhor das hipóteses, apenas presumindo que se trata de resistência a uma ou outra doença. Provavelmente, esta inadvertida falta de precisão na descrição de resistência a doenças presentes nos catálogos e folhetos é fruto da ausência de uma boa revisão por profissional da área ou de sofríveis traduções de catálogos estrangeiros.

A seguir, são apresentados alguns exemplos extraídos de catálogos e folhetos recentes produzidos por algumas das principais companhias com atuação no Brasil (Tabela 1). Indo além da simples crítica, são dadas sugestões de padronização das informações (Tabela 2), sem a intenção de criar novos padrões alternativos àqueles usados na comunidade científica internacional. Essas informações, abreviaturas e legendas podem ser usadas como modelo e extrapoladas para outras culturas.

Desta forma, esta carta tem a finalidade de servir de alerta às companhias de semente atuando no Brasil, já que informações de má qualidade podem resultar na indesejável dificuldade de interpretação por parte do usuário ou mesmo em desgastantes questões jurídicas associadas a potenciais propagandas enganosas. 
Tabela 1. Exemplos de problemas de identificação da doença ou do patógeno para o qual cultivares de tomate (T) e pimentão (P) apresentam resistência, de acordo com catálogos de algumas companhias de sementes.

\begin{tabular}{|c|c|c|}
\hline $\begin{array}{l}\text { No catálogo: } \\
\text { resistência/tolerância a: }\end{array}$ & Como deveria ser & Observação \\
\hline Vírus; Tobamovírus (P) & $\begin{array}{l}\text { TMV, ToMV, outras espé- } \\
\text { cies de tobamovirus }\end{array}$ & $\begin{array}{l}\text { Dezenas de vírus infectam o pimentão, e a cultivar } \\
\text { não é resistente a todas elas. Se a resistência é } \\
\text { somente a alguma espécie, estirpe(s) do vírus, } \\
\text { estas devem ser indicadas. }\end{array}$ \\
\hline Phytophthora $(\mathrm{P}, \mathrm{T})$ & Pc ou Pi ou Pp & $\begin{array}{l}\text { Várias espécies de } P \text { hytophthorainfectam o } \\
\text { pimentão e o tomate, e estas devem ser } \\
\text { discriminadas: P. capsici, } P \text {. infestans } P \text {. parasitica }\end{array}$ \\
\hline Mosaico $(P)$ & $\begin{array}{l}\text { PVY ou CMV ou TMV ou } \\
\text { outro }\end{array}$ & $\begin{array}{l}\text { Vários vírus induzem sintomas de mosaico em } \\
\text { pimentão. Se a resistência é somente para alguma } \\
\text { espécie ou estirpe de vírus, esta deve ser } \\
\text { especificada. }\end{array}$ \\
\hline $\begin{array}{l}\text { VYB; Y; PMMV 1,2; PeMVV } \\
1,2,3,4 \text { (P) }\end{array}$ & (Identificação impossível) & $\begin{array}{l}\text { A abreviatura do nome da espécie do vírus e suas } \\
\text { estirpes deve ser derivada do nome em inglês, de } \\
\text { acordo com norma internacional. }\end{array}$ \\
\hline $\begin{array}{l}\text { Grupo do vírus } Y \text { da batata } \\
\text { (P) }\end{array}$ & $\begin{array}{l}\text { Identificar a espécie de } \\
\text { potyvirus. }\end{array}$ & $\begin{array}{l}\text { A nomenclatura indicada é defasada. A espécie do } \\
\text { gênero Potyvirustem que ser indicada. }\end{array}$ \\
\hline $\begin{array}{l}\mathrm{PVY}=\text { mosaico do } \\
\text { pimentão }(\mathrm{P})\end{array}$ & PVY & $\begin{array}{l}\text { Indicação da abreviatura correta da espécie do } \\
\text { vírus, porém com nome de doença que pode ser } \\
\text { causada por outro vírus. }\end{array}$ \\
\hline Requeima $(P)$ & $\mathrm{Pc}$ & $\begin{array}{l}\text { A doença não é reconhecida como requeima em } \\
\text { todo o país, recebendo outras denominações mais } \\
\text { freqüentes, como podridão-de-fitóftora, murcha-de- } \\
\text { fitóftora, pé-preto, dentre outras. }\end{array}$ \\
\hline Mancha-negra, Stip (P) & (Sem informação) & $\begin{array}{l}\text { Esta doença não tem sua etiologia bem definida e } \\
\text { sua presença aparentemente não está registrada no } \\
\text { Brasil. }\end{array}$ \\
\hline Nematóide $(P, T)$ & $\mathrm{Mi}-1, \mathrm{Mj}, \mathrm{Ma}$ & $\begin{array}{l}\text { Várias espécies de nematóides atacam o pimentão } \\
\text { e o tomate. A espécie em questão e a raça, quando } \\
\text { existente na espécie, deve estar identificada. }\end{array}$ \\
\hline $\begin{array}{l}\text { Fusarium, Stemphylium, } \\
\text { Verticillium (T) }\end{array}$ & Ss-1, Fol-2, Va-1 & $\begin{array}{l}\text { A espécie e a raça do patógeno (quando existente) } \\
\text { devem ser indicadas. }\end{array}$ \\
\hline Enrolamento das raízes $(T)$ & (Sem informação) & Doença não conhecida. \\
\hline V=Verticiliun $(T)$ & Va-1 ou Va-2 & $\begin{array}{l}\text { A espécie e a raça do patógeno devem ser } \\
\text { indicadas. O gênero do fungo está redigido de } \\
\text { forma incorreta. }\end{array}$ \\
\hline F1=Fusariun-R1 (T) & Fol-1 & $\begin{array}{l}\text { A espécie do patógeno deve ser indicada. } 0 \\
\text { gênero do fungo está redigido de forma incorreta }\end{array}$ \\
\hline
\end{tabular}


Tabela 2. Proposta de abreviaturas a serem usadas nas legendas de catálogos e folhetos de cultivares de pimentão e tomate.

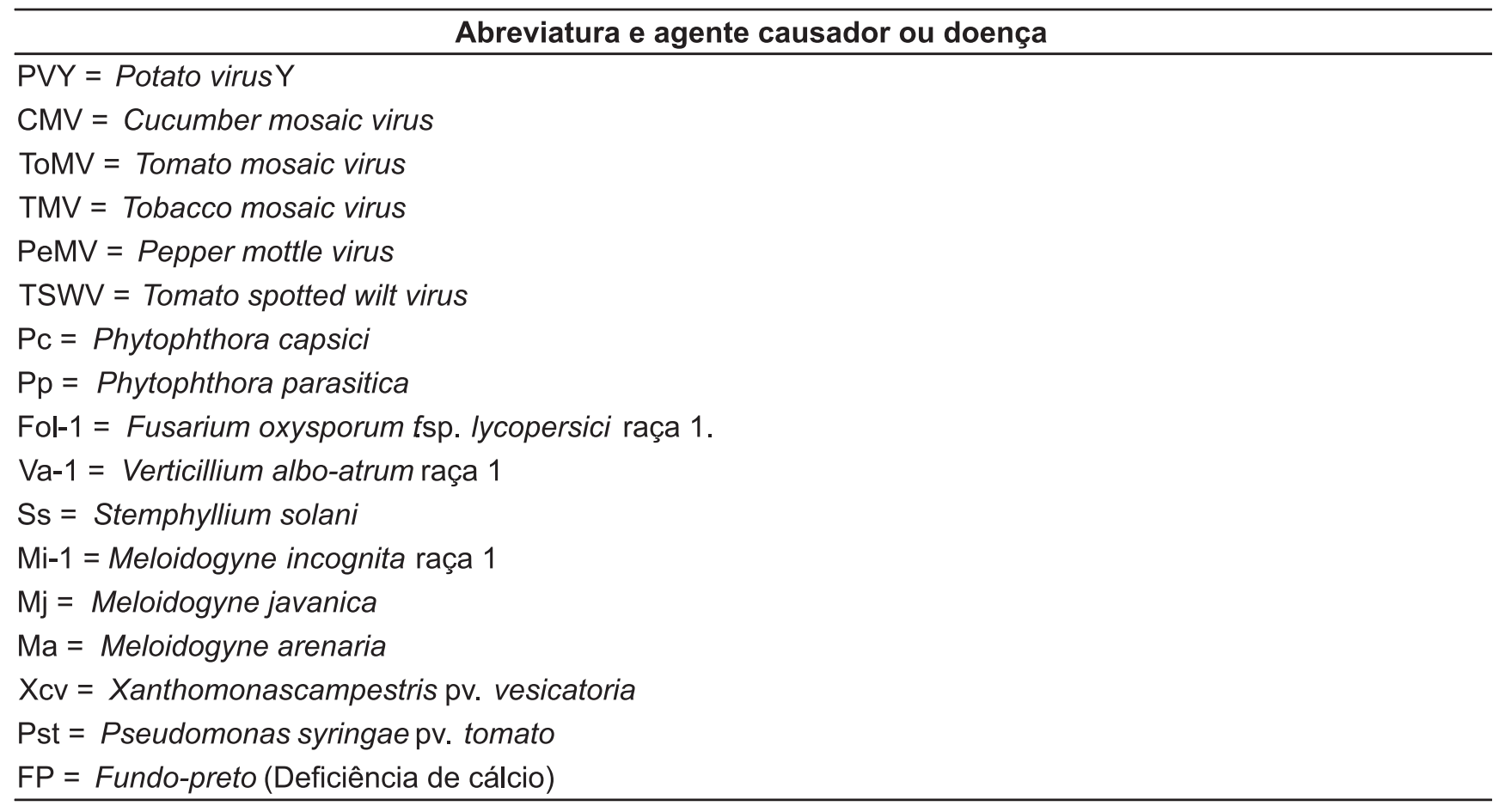

